RGB-D derinlik

kamerasının farklı

görüntüleme

mesafelerinde veri

doğruluğunun

incelenmesi

\section{Examination of the data accuracy of a RGB-D depth camera at different viewing distances}

Arş. Gör. Tamer Çelakıl

İstanbul Üniversitesi Diş Hekimliği Fakültesi, Protetik Diş Tedavisi A.D., İstanbul

Orcid ID: 0000-0002-8085-6356

Geliş tarihi: 3 Nisan 2019

Kabul tarihi: 9 Aralık 2019

doi: 10.5505/yeditepe.2020.96658

\section{Yazışma adresi:}

Arș. Gör. Tamer Çelakıl

İstanbul Üniversitesi Diş Hekimliği Fakültesi,

Protetik Diş Tedavisi A.D., İstanbul-Türkiye

Tel: 02124142020

E-mail: tamer.celakil@istanbul.edu.tr
ÖZET

Amaç: Bu çalışmanın amacı, piyasaya yeni çıkan ve derinlik ile renk bilgisinin elde edilebildiği Intel RealSense D415 kamerasının farklı obje uzaklıklarındaki veri doğruluğunu incelemektir.

Gereç ve Yöntem: Derinlik sensörlü kamera hazır

üretilmiş bir kulak modelinden $22 \mathrm{~cm}, 44 \mathrm{~cm}$ ve $70 \mathrm{~cm}$ uzaklıklara yerleştirilerek kulak modelinin üç boyutlu görüntüleri elde edildi. Kulak modeli üzerinde işaretlenen 3 anatomik nokta arasındaki ( $A, B$ ve C) mesafeler bilgisayar ortamında ölçüldü. Bu verilerin doğruluğunu karşılaştırabilmek amacıyla noktalar arası mesafeler kulak modeli üzerinde dijital bir kumpas ile ayrıca ölçüldü. Elde edilen 4 grubun sonuçları arasındaki anlamlııkların belirlenebilmesi için Friedman testi ve Bonferroni Dunn testi uygulandı.

Bulgular: $22 \mathrm{~cm}, 44 \mathrm{~cm}, 70 \mathrm{~cm}$ ve kontrol olarak ölçülen gruplardaki A, B ve C mesafeleri arasında istatistiksel olarak anlamlı farklılıklar saptandı $(p<0.01) .70 \mathrm{~cm}$ uzaklıktan elde edilen 3B görüntülerde noktalar arası mesafeler, $22 \mathrm{~cm}, 44 \mathrm{~cm}$ ve kontrol gruplarına göre anlamlı şekilde yüksek bulundu ve veri güvenilirliğinin anlamlı derecede düşük olduğu gözlemlendi $(p<0.05)$.

Sonuç: $22 \mathrm{~cm}$ ve $44 \mathrm{~cm}$ grupları arasındaki veriler değerlendirildiğinde anlamlı bir farklılık olmadığı ve bu verilerin gerçek değerler (kontrol) ile de anlamlı derecede uyumlu olduğu gözlemlenmiştir. Bu sonuçlar yorumlandığında, mevcut kameranın $22 \mathrm{~cm}$ ve $44 \mathrm{~cm}$ çalışma

mesafelerinde yüksek veri güvenilirliği sağladığı sonucu ortaya çıkmaktadır.

Anahtar kelimeler: Derinlik sensörü, antropometrik ölçüm, dijital yüz ölçüsü.

SUMMARY

Aim: The aim of this study is to examine the accuracy of data of the newly announced Intel RealSense D415 camera, where depth and color information can be obtained, on different object distances.

Materials and Method: The depth sensor camera was placed at a distance of $22 \mathrm{~cm}, 44 \mathrm{~cm}$ and $70 \mathrm{~cm}$ from a prefabricated ear model to obtain three-dimensional images of the ear model. The distances between the 3 anatomical points marked on the ear model ( $\mathrm{A}, \mathrm{B}$ and $\mathrm{C}$ ) were measured on computer. To compare the accuracy of these data, the distances between the points were measured with a digital caliper on the ear model. Friedman test and Bonferroni Dunn test were used to determine the significance between the results of the 4 groups.

Results: There were statistically significant differences between $\mathrm{A}, \mathrm{B}$ and $\mathrm{C}$ distances in the groups measured as $22 \mathrm{~cm}, 44 \mathrm{~cm}, 70 \mathrm{~cm}$ and control $(p<0.01)$. The distance between the points in $70 \mathrm{~cm}$ group was significantly higher than the control group, and the reliability of this data was significantly lower than the control group $(p$ 
$<0.05)$.

Conclusion: When the data between $22 \mathrm{~cm}$ and $44 \mathrm{~cm}$ groups were evaluated, it was observed that there was no significant difference and these data were significantly compatible with the actual values (control). When these results are interpreted, it is concluded that the current camera provides high data reliability at working distances of $22 \mathrm{~cm}$ and $44 \mathrm{~cm}$.

Keywords: Depth sensor, anthropometric measurement, digital face impression.

\section{GiRiş}

Diş hekimliğinin özel uzmanlık alanlarından birisi olan yüz protezleri, doğumsal ya da kazanılmış yüz defektlerinin çeşitli epitezler ile rehabilitasyonu için uzun yıllardır tercih edilmektedir. Geleneksel yüz protezi uygulamalarında, defekt bölgesinin alçı modelini doğru bir şekilde elde edilebilmek için farklı ölçü materyalleri kullanılmaktadır. Epitez üretimi öncesinde; defekt bölgesinin ölçülerinin alınması esnasında enfeksiyon riski, ölçü materyalinin deformasyonu veya defekt bölgesinin ölçü alımına uygun olmayışı gibi bazı zorluklarla karşılaşılabilmektedir. ${ }^{1,2}$ Böyle durumlar için literatürde dijital ölçü tekniklerinin tercih edilmesi gerekliliği bildirilmiştir. ${ }^{3-5}$ Ancak güncel dijital ölçü tekniklerinin de invaziv olması (tomografiler ile veri elde etme tekniği), pahalı olması veya zorlayıcı teknik ekipmana ihtiyaç duyulması gibi dezavantajları bulunmaktadır. ${ }^{6-8}$ Yüz bölgesindeki sağlıklı olan ya da olmayan bölgelerin derinliğini ve boyutunu kolay, ucuz ve dokuya zarar vermeden elde edebilmek için yeni teknolojilerin kullanılmasına ihtiyaç vardır.

Dijital teknolojilerin gelişimi, farklı sektörlerde yeni ürün çeşitliliğini de birlikte getirmiştir. 2010 yılında Microsoft firması, yapısında bulundurduğu sensörlerin görüş alanındaki bir sahnenin derinlik bilgisini elde edebilen ve derinlik sensörlü kamera (RGB-D) teknolojisinin ilk ürünü olan Microsoft Kinect kamerasını tanıtmıştır. ${ }^{9} \mathrm{Bu}$ kameralar, aynı firmanın Xbox oyun konsollarında sanal gerçeklik (VR) ve arttırılmış gerçeklik (AR) deneyimlerini kullanıcılara sunabilmek için üretilmiştir. Böylece; insan gözünün algılayabildiği renk, ışık ve derinlik hissinin RGB-D kameralar ile de elde edilebilmesinin ve bu verilerin kayıt altına alınabilmesinin önü açılmıştır. Nitekim geçtiğimiz 10 yıl içerisinde, Kinect'in tanıtımında sonra, bir çok farklı üretici firma kendi RGB-D

kamerasını üreterek piyasaya sürmüştür. ${ }^{10,11}$ Temel amacı aynı, amacın elde edilmesinde kullanılan tekniğin farklı olduğu RGB-D kameralar, bir çok araştırmacının da dikkatini çekerek farklı alanlarda literatüre konu olmuştur. 2018 yılının Kasım ayında Intel firması, yeni nesil RGB-D kamerası olan RealSense D4 (Intel RealSense, Kaliforniya, Amerika) serisini tanıtmıştır. Pasif stereo eşleştirme ve aktif kızılötesi tarama tekniğini bir arada kullanarak yüksek çözünürlükte sahne derinliği bilgisini renk verileri ile birlikte elde etme üzerine kurulu olan bu RGB-D kameralar, kullanım alanına göre farklı teknik altyapıları barındıran D415 ve D435 modelleri ile kullanıcalara sunulmuştur. Üretici firma; kameranın minimum ve maksimum veri elde etme mesafesi, lazer ışığı yoğunluğu, birim pikseldeki veri yoğunluğu ve renk ile derinlik dokusunun çözünürlüğü gibi özellikleri ön ayarlar ile standardize etmiştir. Bununla birlikte, bu kameralar açık kaynaklı bir bilgisayar

programı ile desteklenmektedir ve bu program vasıtasıyla intiyaçlar doğrultusunda farklı veri elde etme ayarlarının kullanıcılar tarafından seçilebilmesine ya da değiştirilebilmesine olanak tanınmıştır. ${ }^{12}$

Antropometri, yapısal insan vücudu ölçüleri ile ilgilenen bir bilim alanıdır ve bu özel alanda insan vücuduna ait yükseklik, genişlik, derinlik, uzunluk ve hacim gibi ölçümler incelenir. ${ }^{13}$ RGB-D kameraların sağlık alanında kullanımı ile ilgili yapılmış olan çok az sayıdaki çalışmaya bakıldığında, bu cihazların antropometrik ölçümler için kullanılabileceğine dair veriler ortaya çıkmaktadır. ${ }^{10,11,14,15}$ Ancak, RGB-D kameralarının kullanımında farklı odak uzaklıklarının veri doğruluğuna olan etkisini ortaya koyan bir çalışma bulunmamaktadır. Bu sebeple; bu çalışmada, derinlik ve renk bilgisinin elde edileceği objeye olan sensör uzaklığının, Intel RealSense D415 derinlik sensörlü kamerasının veri doğruluğuna ve güvenilirliğine olan etkisini belirleyebilmek amaçlanmıştır.

\section{GEREÇ VE YÖNTEM}

Bu çalışmada, Intel RealSense D415 derinlik sensörlü kamera ve hazır olarak üretilmiş bir kulak modeli (4D Master, Çin) kullanılmıştır. Kulak modelinin üç boyutlu (3B) görüntüsünü elde edebilmek ve bu görüntülerin veri doğruluğunu karşılaştırabilmek için kameranın kulak modelinden 3 farklı mesafede $(22 \mathrm{~cm}, 44 \mathrm{~cm}$ ve $70 \mathrm{~cm}$ ) konumlandırılmasına karar verilmiştir. Bu mesafeler belirlenirken kamera üreticisinin açıklamış olduğu teknik özellikler ve minimum/maksimum çalışma aralıkları dikkate alınmıştır. ${ }^{12}$ Çalışma mesafeleri belirlendikten sonra kulak modeli üzerinde 3 anatomik nokta (A: antiheliks; B: tragus; C: lobül) işaretlenmiştir (Resim 1).

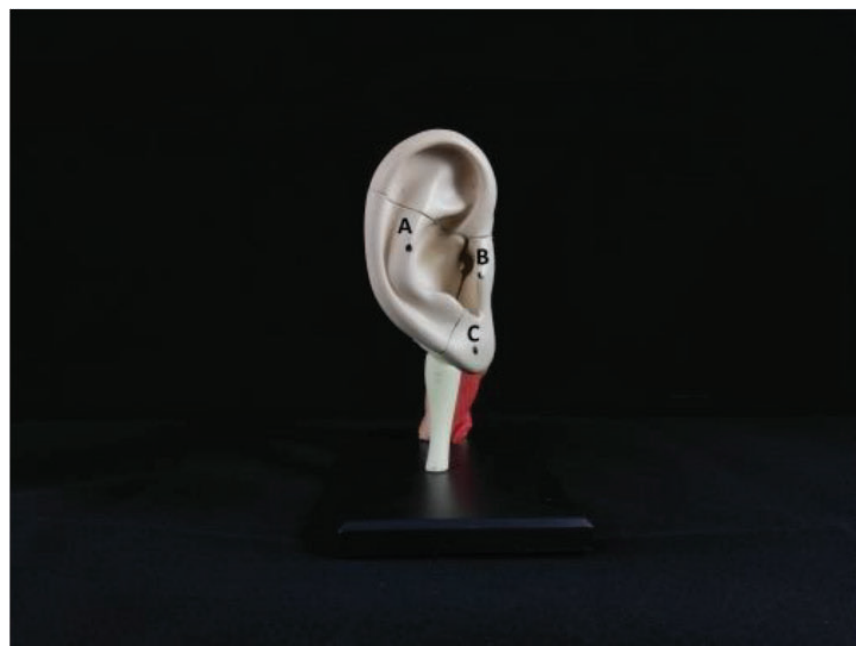

Resim 1. Çalıșmada kullanılan kulak modeli ve anatomik işaretlemeler. 
Bu anatomik noktalar arası mesafelerin ( $A-B$ arası mesafe, $\mathrm{A}-\mathrm{C}$ arası mesafe, $\mathrm{B}-\mathrm{C}$ arası mesafe, $\mathrm{A}-\mathrm{B}-\mathrm{C}$ arası toplam mesafe) gerçek değerlerini belirleyebilmek için $0.01 \mathrm{~mm}$ hassasiyetinde ölçüm yapabilen bir dijital kumpas (Tomax, İstanbul, Türkiye) kullanılmıştır. Dijital kumpas ile noktalar arası mesafeler 10 kez ölçülmüş ve ortalaması alınarak kontrol grubu oluşturulmuştur.

3B görüntü elde ederken ışık ve gölge gibi çevre şartlarını standardize edebilmek için kulak modeli bir ışık kutusuna yerleştirilmiştir (Resim 2).

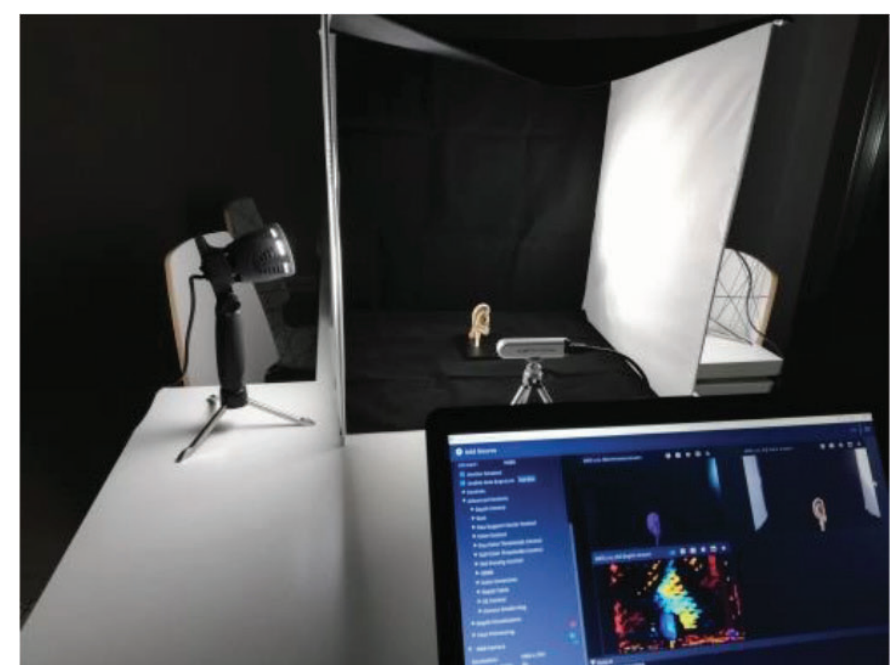

Resim 2. Kulak modelinin ışık standardizasyonu ve 3B görüntünün elde edilmes işlemi.

Bu ışık kutusu 2 adet LED ışık kaynağı ile aydınlatılmış ve işlem esnasında ışık kaynaklarının pozisyonu

değiştirilmemiştir. Standardizasyon sağlandıktan sonra Intel RealSense D415 kamerası bilgisayara USB 3.0 kablosu vasıtasıyla bağlanarak yine üretici firmanın kullanıcılara sunmuş olduğu Intel RealSense Viewer (Intel RealSense Viewer, Kaliforniya, Amerika) programı çalıştırıımıştır. Daha sonra D415 kamerası, kulak modelinden $22 \mathrm{~cm}$ uzaklığa yerleştirilerek ardışık olarak 10 adet görüntü elde edilmiştir $(n=10)$. Derinlik ve renk dokusu verilerini içeren bu 3B görüntüler. PLY (polygon model dosyası) dosyaları olarak bilgisayara kaydedilmiştir (22 $\mathrm{cm}$ grubu). Aynı işlemler kulak modelinden $44 \mathrm{~cm}(44 \mathrm{~cm}$ grubu) ve $70 \mathrm{~cm}$ (70 cm grubu) uzaklığa kameranın yerleştirilmesiyle tekrarlanmış ve .PLY dosyaları bilgisayara kaydedilmiştir (ntoplam=30). D415 kamerasıyla farklı uzaklıklardan elde edilen toplamda 30 adet. PLY dosyası, 3B modellerin son haline getirilebilmesi ve anatomik noktalar arası ölçümlerin yapılabilmesi için açık kaynak erişime sahip MeshLab programına aktarılmıştır. MeshLab programına aktarılan 3B görüntülerde, kulak modeline ait veriler haricindeki çevre derinlik ve renk doku verileri silinerek .STL dosyaları oluşturulmuştur (Resim 3).
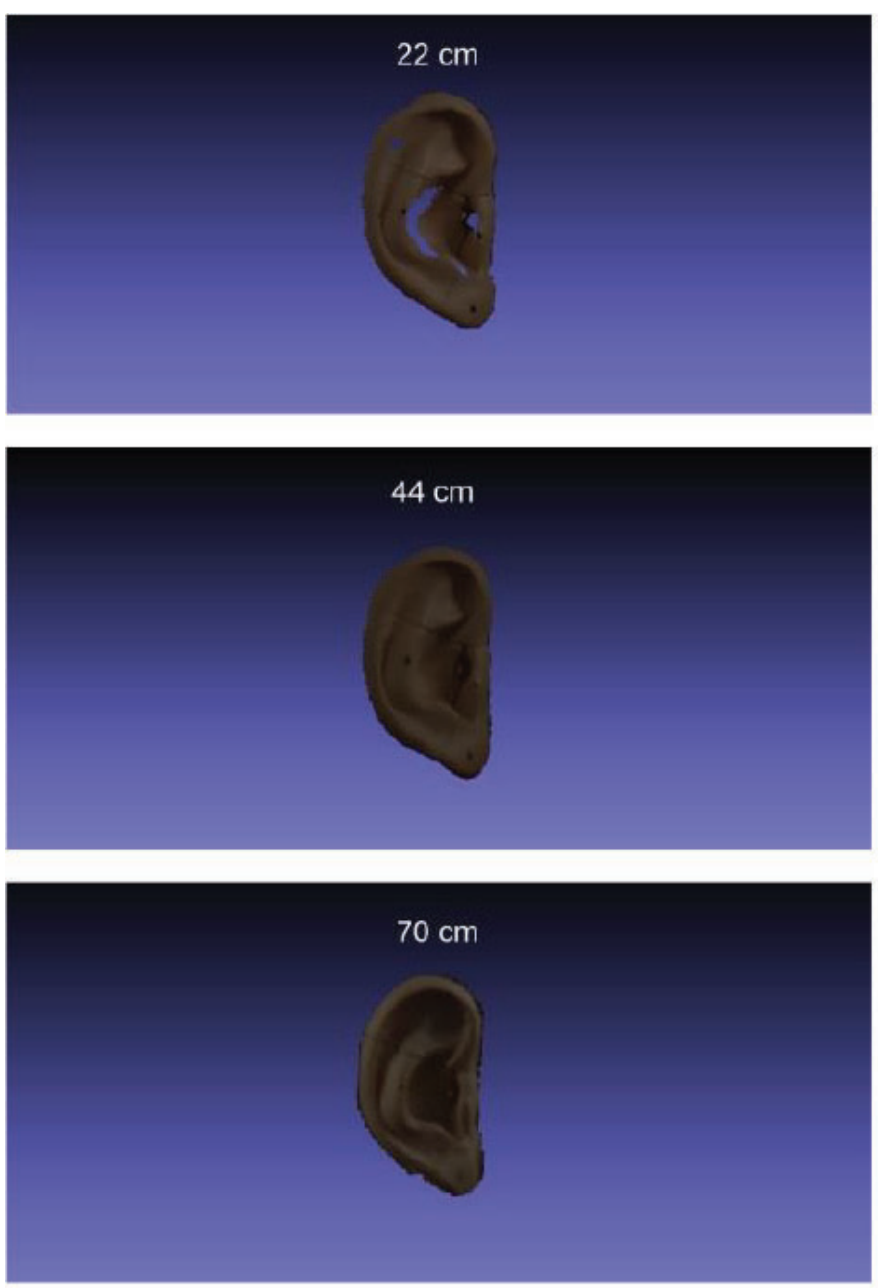

Resim 3. Farklı gruplardaki 3B kulak modellerinin MeshLab programındak görünümü.

Daha sonra 3 çalışma grubunun her bir görüntüsü ayrı ayrı değerlendirilerek noktalar arası mesafeler ölçülmüş ve kaydedilmiştir.

İstatistiksel analizler için NCSS (Number Cruncher Statistical System) 2007 (Kaysville, Utah, USA) programı kullanıldı. Çalışma verileri değerlendirilirken tanımlayıcı istatistiksel metodlar (ortalama, standart sapma, medyan) kullanıldı. Normal dağılım göstermeyen değişkenlerin takiplerinin değerlendirilmesinde Friedman test ve ikili karşılaştırmaların değerlendirilmesinde Bonferroni Dunn test kullanıldı. Anlamlıık en az $\mathrm{p}<0.05$ düzeyinde değerlendirildi.

\section{BULGULAR}

A, B ve C noktaları arasındaki mesafelerin gruplara göre istatistiksel olarak değerlendirilmesi yapıldı (Tablo 1).

$22 \mathrm{~cm}, 44 \mathrm{~cm}, 70 \mathrm{~cm}$ ve kontrol olarak ölçülen A-B mesafeleri arasında istatistiksel olarak anlamlı farklılık saptanmıştır $(p<0.01)$. 
Tablo 1. Gruplara Göre A, B, C Noktaları Arası Ölçülen Mesafelerin Değerlendirilmesi

\begin{tabular}{|c|c|c|c|c|}
\hline & & A-B mesafesi & A-C mesafesi & B-C mesafesi \\
\hline & $\mathbf{n}$ & $\overline{\text { Ort } \pm \text { Ss (Medyan) }}$ & Ort \pm Ss (Medyan) & Ort \pm Ss (Medyan) \\
\hline 22 cm grubu & 10 & $18,17 \pm 0,04(18,2)$ & $27,62 \pm 0,09(27,6)$ & $16,32 \pm 0,05(16,3)$ \\
\hline $44 \mathrm{~cm}$ grubu & 10 & $18,31 \pm 0,13(18,3)$ & $27,50 \pm 0,22(27,5)$ & $16,43 \pm 0,20(16,4)$ \\
\hline $70 \mathrm{~cm}$ grubu & 10 & $18,93 \pm 0,27(18,9)$ & $28,24 \pm 0,27(28,4)$ & $16,98 \pm 0,14(17)$ \\
\hline Kontrol grubu & 10 & $18,20 \pm 0,03(18,2)$ & $27,62 \pm 0,05(27,6)$ & $16,37 \pm 0,08(16,4)$ \\
\hline$p$ & & ${ }^{a} 0,001 * *$ & ${ }^{a} 0,001^{* * *}$ & ${ }^{a} 0,001 * *$ \\
\hline $22 \mathrm{~cm}-44 \mathrm{~cm}$ & & ${ }^{b} 0,182$ & ${ }^{b} 0,846$ & ${ }^{b} 1,000$ \\
\hline $22 \mathrm{~cm}-70 \mathrm{~cm}$ & & ${ }^{b} 0,001 * *$ & ${ }^{b} 0,015^{*}$ & ${ }^{b} 0,001 * *$ \\
\hline $22 \mathrm{~cm}$-kontrol & & ${ }^{b} 1,000$ & ${ }^{b} 1,000$ & ${ }^{b} 1,000$ \\
\hline $44 \mathrm{~cm}-70 \mathrm{~cm}$ & & ${ }^{b} 0,146$ & ${ }^{b} 0,001$ ** & ${ }^{b} 0,006^{* *}$ \\
\hline $44 \mathrm{~cm}$-kontrol & & ${ }^{b} 0,846$ & ${ }^{b} 0,599$ & ${ }^{b} 1,000$ \\
\hline $70 \mathrm{~cm}$-kontrol & & ${ }^{b} 0,001 * *$ & ${ }^{b} 0,026^{*}$ & $0,004 * *$ \\
\hline
\end{tabular}

Yapılan ikili karşılaştırmalar sonucunda; $70 \mathrm{~cm}$ uzaklıktan ölçülen A-B mesafesi, $22 \mathrm{~cm}$ uzaklıktan ve kontrol olarak ölçülen uzaklıktan daha fazladır (sırasıyla $p=0.001$; $p=0.001 ; p<0.01)$. Diğer grupların $A-B$ mesafeleri arasında istatistiksel olarak anlamlı farklılık saptanmamıştır (p>0.05) (Grafik 1).

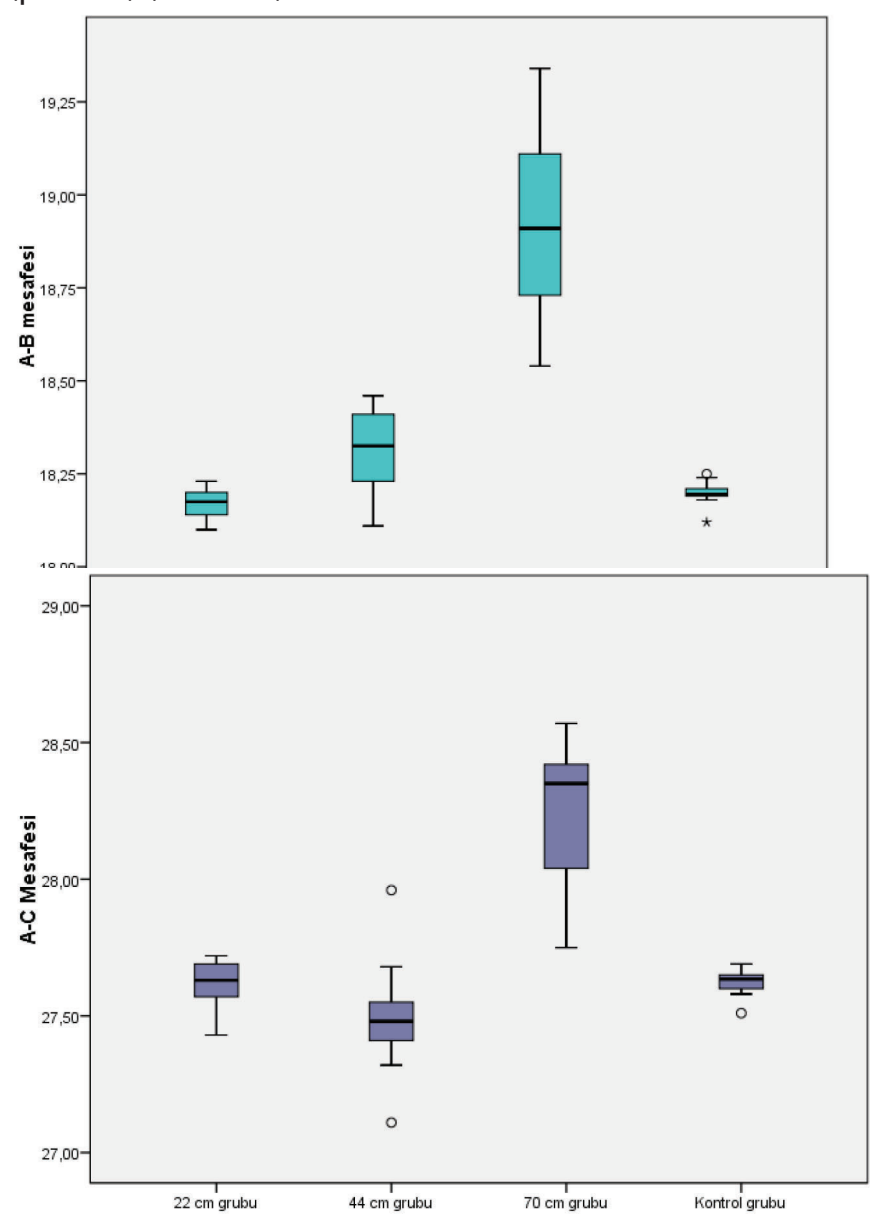

Grafik 2. A-C mesafelerinin dağılımı.
$22 \mathrm{~cm}, 44 \mathrm{~cm}, 70 \mathrm{~cm}$ ve kontrol olarak ölçülen B-C mesafeleri arasında istatistiksel olarak anlamlı farklılık saptanmıştır $(p=0.001 ; p<0.01)$. Yapılan ikili karşılaştırmalar sonucunda; $70 \mathrm{~cm}$ uzaklıktan ölçülen $\mathrm{B}-\mathrm{C}$ mesafesi, $22 \mathrm{~cm}, 44 \mathrm{~cm}$ uzaklıktan ve kontrol olarak ölçülen uzaklıktan daha fazladır (sırasıyla $p=0.001 ; p=0.006 ; p=0.004$; $\mathrm{p}<0.01)$. Diğer grupların $\mathrm{B}-\mathrm{C}$ mesafeleri arasında istatistiksel olarak anlamlı farklıık saptanmamıştır ( $p>0.05)$ (Grafik 3).

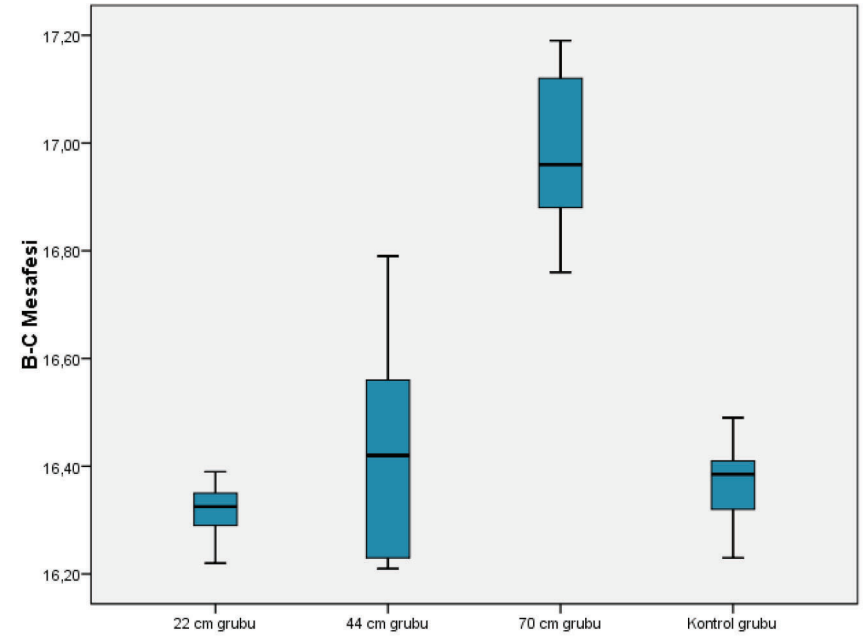

Grafik 3. B-C mesafelerinin dağılımı.

\section{TARTIŞMA}

Bu çalışmada Intel RealSense D415 kamerası farklı çalışma mesafelerine yerleştirilmiş ve hazır üretilmiş bir kulak modelinin 3B görüntüleri elde edilmiştir. Elde edilen bu 3B görüntülerin antropometrik ölçümleri gruplara göre karşılaştırılmıştır. Çalışmamızda elde edilen sonuçlarda; $70 \mathrm{~cm}$ uzaklıktan elde edilen 3B görüntülerde noktalar arası mesafeler, $22 \mathrm{~cm}, 44 \mathrm{~cm}$ ve kontrol gruplarına göre anlamlı şekilde yüksek bulunmuş ve veri güvenilirliğinin anlamlı derecede düşük olduğu gözlemlenmiştir. $22 \mathrm{~cm}$ ve $44 \mathrm{~cm}$ grupları arasındaki veriler değerlendirildiğinde anlamlı bir farklıık olmadığı ve bu verilerin gerçek değerler (kontrol) ile de anlamlı derecede uyumlu olduğu gözlemlenmiştir. Bu sonuçlar yorumlandığında, mevcut kameranın $22 \mathrm{~cm}$ ve $44 \mathrm{~cm}$ çalışma mesafelerinde yüksek veri güvenilirliği sağladığı sonucu ortaya çıkmaktadır.

Bu çalışmada tercih edilen görüntü alma mesafeleri kamera üreticisinin teknik dökümanlarında belirlemiş olduğu minimum ve maksimum görüntü elde etme verileri ile ilişkilidir. ${ }^{12} \mathrm{Bu}$ teknik bilgiler değerlendirildiğinde fabrika verilerine göre D415 kamerasının minimum çalışma mesafesi yaklaşık olarak $44 \mathrm{~cm}^{\prime}$ dir. Ancak Intel RealSense Viewer programı ile kullanıcılara sunulan özellikler sayesinde minimum çalışma mesafesi yaklaşık 22cm olarak ayarlanabilmektedir. Bu çalışmada, kamera odak noktası ile obje arasındaki mesafe azaldıkça piksel başına düşen verinin arttığı ve daha net görüntülerin elde edildiği görülmüştür. Ancak, $22 \mathrm{~cm}$ çalışma mesafesinde görüntüler net olmasına rağmen verinin elde edilemediği artifakt alanların da ortaya çıktığı görülmek- 
tedir. Üretici firma bu durumu insan görüşüne benzetmektedir. ${ }^{12}$ Tıpkı insan gözü gibi, birden fazla kameranın belirli bir objeye odaklanabildiği ve görüntüyü netleyebildiği minimum bir mesafe vardır ve obje daha fazla yaklaştırılığında flu bir görüntü ortaya çıkmaktadır. $70 \mathrm{~cm}$ çalışma mesafesi ise, yapılan çalışma

öncesindeki pilot değerlendirmede, kulak modeli üzerindeki noktaların elde edilecek olan 3B görüntüde net olarak belirlenebildiği maksimum mesafe olduğu için tercih edilmiştir. Carfagni ve ark.'nın ${ }^{16}$ yaptığı çalışmada D415 kamerasının $15 \mathrm{~cm}-50 \mathrm{~cm}$ aralığındaki görüntü alma işleminde rekonstrüksiyon hatasının ortalama $1 \mathrm{~mm}$ olduğu bildirilmiştir. Ayrıca odak noktası ile obje arasındaki mesafe azaldıkça verinin elde edilemediği bazı alanların ortaya çıktığı belirtilmiştir. Ten Harkel ve ark. ${ }^{17}$ yaptıkları bir çalışmada, Intel firmasının bir önceki nesil F200 kamerasının derinlik doğruluğunu sağlıklı ve yüz felçi geçirmiş bireylerde test etmiştir. İki grup arasında veri hassasiyetinde bir farklılık olmadığını ve F200 serisinin güvenilir olduğunu, ancak, kameranın bireye olan uzaklığının veri doğruluğunu etkilediğini ve en yüksek doğruluğun $35 \mathrm{~cm}$ mesafeden elde edildiğini bildirmişlerdir. Bu bilgiler, mevcut çalışmanın sonuçları ile karşılaştırıldığında benzerlik göstermektedir.

Doğumsal ya da kazanılmış yüz defektlerinin cerrahi olarak düzeltilemediği durumlarda yüz protezlerinden faydalanılmaktadır. Yüz protezleri, bu defektlere sahip bireylerin yaşam kalitesini arttırmaktadır. Dings ve ark.'nın ${ }^{18}$ yaptıkları anket çalışmasında geleneksel yöntemlerle üretilmiş yüz protezi kullanan bireyler değerlendirilmiş ve yüz protezlerinin ömrünün uzatılabilmesi için malzeme özelliklerinde ve üretim tekniklerinde yeniliklere intiyaç duyulduğu bildirilmiştir. Son yıllarda yüz protezlerinin dizayn ve üretiminde 3B teknolojosi kullanımının hekimlere ve araştırmacılara umut verici sonuçlar sunabileceği düşünülmektedir. Yadav ve ark.'nın ${ }^{19}$ yaptığı çalışmada bilgisayarlı tomografi (BT) kullanılarak kulak protezi dizaynı ve üretimi gerçekleştirilmiştir. Ancak BT uygulaması invaziv bir işlem olduğu için dezavantaja sahiptir. Ciocca ve ark. ${ }^{20}$ ise burun protezi üretiminde lazer tarama teknolojisinden faydalanmıştır. Ancak bu çalışma değerlendirildiğinde, tarama işleminin uzun sürmesi, mevcut lazer cihazının pahalı oluşu ve portatif olmayışı gibi dezavantajların olduğu görülmektedir. Bu sebeple yüz protezlerinin üretiminde RGB-D kameralarının kullanımına intiyaç duyulabileceği düşünülmektedir. Çünkü literatür incelendiğinde, RGB-D kamerası kullanılarak yüz protezi üretimi yapılmış herhangi bir çalışma bulunmamaktadır. Bununla birlikte, son dönemde gelişen teknoloji sonucu 3B yazıcıların kullanımı artmaya başlamıştır. Ancak, 3B yazıcı kullanılarak üretilmiş yüz protezi çalışması sayısı yine de çok azdır. Lopez ve ark. ${ }^{21}$ yaptıkları çalışmada, doku mühendisliği ilkeleri ve dijital görüntüleme yazıım platformları kullanılarak hastalara özgü kraniyofasiyal rekonstrüksiyon yapılabileceğini raporlamıştır. Bu açıdan değerlendirildiğinde, RGB-D kameralar ile 3B yazıcıların ortak kullanımı sonucunda ucuz, kolay ve hızlı bir şekilde yüz protezi üretimi gerçekleştirilebileceği düşünülebilir.

\section{SONUÇ}

RGB-D kameralar; Işıkstandardizasyonu, kamera pozisyonu, odak uzaklığı ve bilgisayar programı ön ayarları gibi etkenlerin doğru bir şekilde ayarlandığı şartlarda yüksek güvenilirlikle $3 \mathrm{~B}$ veri elde edilebilmesine olanak sağlamaktadır. Bu sebeple, önümüzdeki dönemde bu yeni nesil kameraların diş hekimliğinde ve tıp alanında daha sık kullanılması muhtemeldir. Bu çalışmanın sonuçlarına bakıldığında, kamera üretici firmalarının kullanım önerileri doğrultusunda hareket edilmesi gerektiği ve bu kameraların teknik özelliklerinin iyi bilinmesi gerekliliği ortaya çıkmaktadır. Mevcut sonuçların desteklenebilmesi ve kameraların rutin olarak diş hekimliği ile tıp alanında kullanım alanı bulabilmesi için daha fazla çalışmaya intiyaç vardır.

\section{KAYNAKLAR}

1. Tanaka Y. New facial impression technique in maxillofacial. Maxillofacial Prosthetics 1979;2:11-14.

2. Bai SZ, Feng ZH, Gao R, Dong Y, Bi YP, et al. Development and application of a rapid rehabilitation system for reconstruction of maxillofacial soft-tissue defects related to war and traumatic injuries. Mil Med Res 2014;1:11.

3. Verdonck HW, Poukens J, Overveld HV, Riediger D. Computer-assisted maxillofacial prosthodontics: a new treatment protocol. Int J Prosthodont 2003;16:326-328.

4. Yoshioka F, Ozawa S, Okazaki S, Tanaka Y. Fabrication of an orbital prosthesis using a noncontact three-dimensional digitizer and rapid-prototyping system. J Prosthodont 2010;19:598-600.

5. Watson J, Hatamleh MM. Complete integration of technology for improved reproduction of auricular prostheses. J Prosthet Dent 2014;111:430-436.

6. Choi JW, Lee JY, Oh TS, Kwon SM, Yang SJ, et al. Frontal soft tissue analysis using a 3-dimensional camera following two-jaw rotational orthognathic surgery in skeletal class III patients. J Craniomaxillofac Surg 2014;42:220226.

7. Lin CY, Hsung TC, Khambay B. Reducing cone beam CT scan height as a method of radiation reduction for photorealistic three-dimensional orthognathic planning. J Craniomaxillofac Surg 2015;43:907-912.

8. Shimizu F, Uehara M, Oatari M, Kusatsu M. Three-dimensional visualization of the human face using DICOM data and its application to facial contouring surgery using free anterolateral thigh flap transfer. J Plast Reconstr Aesthet Surg 2016;69:e1-4.

9. Yang J, Ye X, Li K, Hou C, Wang Y. Color-guided depth recovery from RGB-D data using an adaptive autoregres- 
sive model. IEEE Trans Image Process 2014;23:34433458.

10. Siena FL, Byrom B, Watts $\mathrm{P}$, Breedon P. Utilising the Intel RealSense Camera for Measuring Health Outcomes in Clinical Research. J Med Syst 2018;42:53.

11. Yang K, Wang K, Hu W, Bai J. Expanding the Detection of Traversable Area with RealSense for the Visually Impaired. Sensors (Basel) 2016;16.

12. Intel Şirketi. Erişim bağlantısı: https://realsense.intel. com/compare/. (Erişim tarihi: 24 Mayıs 2018).

13. Norton $K$, Whittingham $N$, Carter $L$, Kerr $D$, Gore $C$, et al. Measurement techniques in anthropometry. Eds: Kevin Norton \& Tim Olds, Anthropometrica, Australia, Unsw Press, 1996,25-75.

14. Kordi M, Haralabidis N, Huby M, Barratt PR, Howatson G, et al. Reliability and validity of depth camera 3D scanning to determine thigh volume. J Sports Sci 2019;37:3641.

15. Bullas AM, Choppin S, Heller B, Wheat J. Validity and repeatability of a depth camera based surface imaging system for thigh volume measurement. J Sports Sci 2016;34:1998-2004.

16. Carfagni M, Furferi R, Governi L, Santarelli C, Servi M, et al. Metrological and Critical Characterization of the Intel D415 Stereo Depth Camera. Sensors (Basel) 2019;19. 17. Ten Harkel TC, Speksnijder CM, van der Heijden $F$, Beurskens $\mathrm{CHG}$, Ingels KJAO, et al. Depth accuracy of the RealSense F200: Low-cost 4D facial imaging. Sci Rep 2017;7:16263.

18. Dings JPJ, Merkx MAW, de Clonie Maclennan-Naphausen MTP, van de Pol P, Maal TJJ, et al. Maxillofacial prosthetic rehabilitation: A survey on the quality of life. J Prosthet Dent 2018;120:780-786.

19. Yadav S, Narayan Al, Choudhry A, Balakrishnan D. CAD/CAM-Assisted Auricular Prosthesis Fabrication for a Quick, Precise, and More Retentive Outcome: A Clinical Report. J Prosthodont 2017;26:616-621.

20. Ciocca L, Fantini M, De Crescenzio F, Persiani F, Scotti R. New protocol for construction of eyeglasses-supported provisional nasal prosthesis using CAD/CAM techniques. J Rehabil Res Dev 2010;47:595-604.

21. Lopez CD, Witek L, Torroni A, Flores RL, Demissie DB, et al. The role of $3 \mathrm{D}$ printing in treating craniomaxillofacial congenital anomalies. Birth Defects Res 2018;110:10551064. 